\title{
Comparison Between the Social Entrepreneurship Support System for College Students in Britain and America and That in China
}

\author{
Cheng $\mathrm{Su}^{1, *}$ \\ ${ }^{1}$ School of Marxism, Zhejiang University, Hangzhou, Zhejiang 310000, China \\ *Corresponding author. Email: 791241729@qq.com
}

\begin{abstract}
Britain and the United States are the developed countries with the origin and rapid development of social entrepreneurship. Social entrepreneurship in both countries has developed in a steady and orderly way thanks to their well-established support systems. This paper lists the current status of the support system for college student social entrepreneurship in China, including universities, government and non-governmental organizations, and compares it with that in Britain and the United States. It summarizes the weaknesses of the support system for college student social entrepreneurship in China, and puts forward several suggestions.
\end{abstract}

Keywords: Social entrepreneurship, Support systems, Comparative study.

\section{INTRODUCTION}

In recent years, social entrepreneurship has attracted more and more attention from the society and academia. Social entrepreneurship can not only solve the employment problem that is widely concerned by the society, but also create humanistic care and social value for the society. American scholar J. Gregory Dees first put forward the concept of social entrepreneurship in 1998, and it has been developing vigorously since then, and has given strong support to government policy support and university education system setting. China's social entrepreneurship originated from the social entrepreneurship Association of Drien University, Hunan University, which was founded by college students in 2006. Since then, social entrepreneurship has gradually entered people's vision. Due to their flexible thinking, strong ability to accept new things, and love for entrepreneurship, college students undoubtedly assume the dominant position of social entrepreneurship in colleges and universities. However, we find that the survival ability of many social entrepreneurship organizations of college students becomes very low once they go out of campus, and many social entrepreneurship organizations disappear or face disintegration. The main reason for this is that entrepreneurial organizations lack certain survival conditions and capabilities, and their support conditions are indeed relatively weak in related aspects.

\section{ANALYSIS ON THE SOCIAL ENTREPRENEURSHIP SYSTEM OF CHINESE COLLEGE STUDENTS}

\subsection{Colleges and Universities Are the Main Channels for College Students to Start Their Own Business}

College students' social entrepreneurship starts from universities. For college students, all the social entrepreneurship projects they carry out are based on universities at the very beginning. It is embodied in the following two aspects: first, school education; second, the school provides relevant channel support. First of all, the school attaches great importance to the education of students' social entrepreneurship ability. At present, Chinese college students' social entrepreneurship is generally based on their professional background. Therefore, in order to let more students know the specific process of social entrepreneurship, the school will set up appropriate courses. Through the survey, more than half of students said their school 
in the aspect of social entrepreneurship have corresponding teaching system and courses, which more than $70 \%$ of the students according to the survey the school pay more and more attention to social entrepreneurship education, the social entrepreneurship education combined with students' professional, multi-angle to transfer knowledge and experience of entrepreneurship students. In addition, in response to the government's call, the school has established a flexible school system and allowed students to suspend their studies and start their own businesses, giving great support to the school policy. In recent years, colleges and universities have been actively providing theoretical and practical platforms for college students to conduct social entrepreneurship, such as comprehensively deploying reform and education work in this field, holding various innovation and entrepreneurship competitions, and promoting related projects. Therefore, school is the cradle of college students' social entrepreneurship and the stage for them to turn their social entrepreneurship from theory into practice.

In addition, colleges and universities are vigorously promoting social entrepreneurship for college students, whose core purpose is to train talents. On the one hand, colleges and universities provide educational support for college students' social entrepreneurship; on the other hand, college students also use their own professional knowledge to promote the re-expansion of college resources. Social entrepreneurship and its education are conducive to changing many problems existing in colleges and universities, such as too narrow professional scope, weak humanistic education, single training mode, obsolete teaching content and dead teaching methods. Thus it can be seen that in the process of social entrepreneurship for college students, colleges and universities are the platform to provide necessary resources at the very beginning, and they really shoulder the responsibility of educating people and serving the society.

\subsection{The Government Is the Official Institution Supported by the Policy of Social Entrepreneurship for College Students}

Government support is a necessary condition for the smooth development of social entrepreneurship of college students. A series of policies and strategies issued by the government have greatly promoted the development of innovation and entrepreneurship. Government support is also more authoritative and powerful. There are two main areas of support, one is the policy, and the other is the special fund. First of all, policy support can provide strong social environment protection for college students' social entrepreneurship. The government has issued relevant preferential policies to support and encourage the development of social entrepreneurship among college students, such as the Opinions on Several Policies and Measures to Vigorously Promote Mass Entrepreneurship and Innovation, which include tax, financing, entrepreneurship training and other aspects. This will undoubtedly be a great help to college students in the early stage of starting a business, enabling them to get through the bottleneck period. The CPC Central Committee strongly supports mass entrepreneurship, comprehensively deploys the innovation-driven development strategy, and stimulates the potential and vitality of innovation and entrepreneurship in the whole society. From 2015 to 2017, it successively issued nine documents, including the Opinions on Policies and Measures for Promoting Mass Entrepreneurship and Innovation (Guo Fa [2015] No. 32). In August 2008, KAB Entrepreneurship Education (China) program was launched in universities across the country; in 2014, the National "Challenge Cup" Innovation and Entrepreneurship Competition was renamed as "Innovation youth" National College Students Entrepreneurship Competition, and nonprofit entrepreneurship competition was set up, covering 2,200 ordinary colleges and universities across the country. This can not only mobilize the enthusiasm of college students to participate in this field, but also provide strong legal protection, so that college students related entrepreneurial activities have a legal guarantee.

\subsection{Social Enterprises Are the Main Source of College Students' Practical Experience in Social Entrepreneurship}

The essence of both social enterprises and social entrepreneurship is entrepreneurship. The only difference is that social enterprises pay more attention to market returns and economic news in the later period, while social entrepreneurship puts more emphasis on social benefits. Social entrepreneurship is not only social, but also public welfare, so it has a certain relationship with the internal of social enterprises. The development of social enterprises over the years can also give some guidance to social entrepreneurship. 
As we know, in order to support enterprises, promote public welfare activities and encourage social entrepreneurship, the government has issued a large number of relevant policies in recent years. College students can take advantage of this advantage in policy to help their social entrepreneurship activities. The most direct way is to get help from social enterprises, so as to solve the trouble at home in terms of capital. Meanwhile, in the process of starting a business, college students can actually get in touch with the operation mode of enterprises, learn enterprise management experience, and then improve their practical operation ability.

In the process of social entrepreneurship, college students can draw lessons from the development of social enterprises. These provide college students with rich social practice experience in social entrepreneurship and further promote the development of social entrepreneurship activities.

\subsection{Ngos Provide Resources and Experience for Social Entrepreneurship}

Ngos not only solve many problems in the process of social entrepreneurship, but also provide a wide range of social resources and social experience for the whole process of entrepreneurship, providing them with a large number of project support, so that the social entrepreneurship activities of college students can be smooth and effective.

College students have not yet entered the society and lack corresponding social relations and social resources. In the stage of social entrepreneurship, they will encounter difficulties from time to time, so they need to rely on the powerful social resources of ngos. Ngos can make full use of their social resources to mobilize the social network to win the greatest social support for the college students who are undertaking social entrepreneurship. In addition, as a bridge between various support systems and college students, NonGovernmental organizations provide comprehensive project support for college students who are engaged in social entrepreneurship, removing many obstacles in the process of social entrepreneurship activities.

Charities are an important part of ngos. Charitable donation plays a pivotal role in the development of social entrepreneurship, because it provides a strong guarantee and supplement for the whole entrepreneurial system of college students. At present, charitable giving mainly comes from enterprises, families and individuals, among which the largest level comes from enterprises. Many entrepreneurs invest in potential start-ups and collaborate strategically. In the process of college students' social entrepreneurship, the lack of funds is often a realistic and embarrassing problem, and charity donation at this time is undoubtedly a timely help, providing financial support for college students' social entrepreneurship, and solving worries for later entrepreneurial activities, so that entrepreneurial activities can proceed smoothly.

Therefore, in the process of continuous development of social entrepreneurship activities, participants can use the social network of ngos to obtain the resources they need, so as to further develop social entrepreneurship.

\section{THE SOCIAL ENTREPRENEURSHIP SUPPORT SYSTEM FOR COLLEGE STUDENTS IN THE UK AND THE US}

\subsection{The Setting of the Education System in Colleges and Universities}

In developed countries, the two most typical social entrepreneurship countries are the United States and the United Kingdom, whose entrepreneurial models are completely different from each other. Social entrepreneurship in the United States is led by social forces and assisted by the government. As early as the 1880 s, some fund organizations, associations and colleges and universities were strong supporting forces for the development of social entrepreneurship in the United States. Most business schools in the United States have set up research centers for social entrepreneurship, such as Harvard University, Stanford University, Yale University, etc., which have set up courses on social entrepreneurship and incorporated them into teaching plans to train social entrepreneurship talents. In September 2004, Harvard Business School established a doctorate in social entrepreneurship.

In Britain, another country with more developed social entrepreneurship, the actual situation is completely opposite to that of the United States. In the UK, more research centers are set up in universities. For example, Cambridge University, The University of London and other famous 
universities have set up relevant centers for research, and set up corresponding entrepreneurship courses, optional courses and other channels to study social entrepreneurship.

\subsection{The Formulation and Implementation of Government Policies}

In terms of the policies related to college students' public welfare activities, the US government mainly takes tax revenue as the main regulation means. For example, the United States implemented the New Chichang Tax Credit program in 2000, which stipulated that tax credits could be applied to the "community development fund" established in underdeveloped areas. The maximum amount of income tax that could be deducted from the investment amount is $39 \%$ if the investment period exceeds 7 years, so as to create job opportunities and promote the economic development of underdeveloped areas. [4] The US Tax Bureau issued relevant policies in 2004, pointing out that as long as public welfare organizations operate together with certain enterprises within a reasonable scope, they are still eligible for tax credits and enjoy relevant preferential policies in this regard.

Compared with the United States, the British government is more supportive of social entrepreneurship activities. First of all, the British government has established the legal status of social enterprise activities., in fact, the British government in 2004 promulgated the company (audit, research, and community enterprises) ordinance, this method from the legal Angle to admit that the legitimacy of public welfare activities, not only from the content on the new definition of public welfare activities, and make clear about the public welfare activities will be in the form of an enterprise as a legal person management, promote the legal development of entrepreneurship activity. Second, the British government has set up special institutions to promote the development of social entrepreneurship. In 2000, the British government decided that national and local governments should be in charge, and established the non-profit Enterprise Organization, the Department for Trade and Industry and the Regional Development Agency. Third, the British government has adopted a large number of relevant policies to support social entrepreneurship. Especially in the financial aspect, the British government has given tax relief to social enterprises. In addition, the UK Department of
Trade and Industry provides financial support, course training and a wealth of information and advice. In order to support social entrepreneurship, the British government has also set up a related fund.

\subsection{Social Enterprises Participate in the Social Entrepreneurship of College Students}

In fact, the social entrepreneurship in The United States is similar to the association of enterprise alliance, and on the basis of the association, the alliance of social entrepreneurs as the main body has been formed. Through these alliances and associations, a large number of technical and training opportunities are provided to the people who need them - college students, which is undoubtedly conducive to their development in this field. In addition, in terms of the form of entrepreneurship, the United States is closely related to social enterprises in this respect.

There are three main forms of social entrepreneurship in the United States: first, social groups rather than companies; the second is another kind of social group, which exists in the form of a company. The third is in the form of trust. In other words, social entrepreneurship in the United States is another form of social organization, and the two are integrated.

In the UK, social organizations and social entrepreneurship among university students promote each other. On the one hand, the UK has made it clear that university students' social entrepreneurship activities can develop continuously with the help of social organization resources. On the other hand, social organizations can also make continuous progress through the social entrepreneurship of college students to improve the social credibility.

\subsection{Support and Cooperation from Ngos}

In the 1970s, ngos gradually developed in the American society because the American people gradually distrust the government's ability to take charge of affairs. Therefore, in order to solve relevant social problems, ngos became important partners of the government in the field of public service. During this period, social entrepreneurship developed rapidly. Obama was also very supportive of social entrepreneurship when he was President of the United States, and raised funds in his own name to strongly support social entrepreneurship. 
Ngos, by contrast, have grown in size in the UK. Britain seems to have long anticipated the economic benefits of social entrepreneurship. As early as the late 18 th century, a number of social entrepreneurship students, working in areas such as green agriculture, fair trade and elderly care, emerged, successfully fostering a large number of well-known social enterprises. [5] In the 1990s, innovation and entrepreneurship were on the rise. In particular, innovative college students kept exploring in cultural fields and high and new technologies, hoping to realize their social value through these entrepreneurial activities. For them, social entrepreneurship is a brand new enterprise, which can realize a unique value and life form and realize their own value.

In addition, charity organizations in developed countries are more closely connected with social entrepreneurship organizations of college students. In addition to important factors such as ngos, another important factor in America's push for social entrepreneurship comes from the philanthropic capital markets. However, with the continuous development of social entrepreneurship in the United States and the rapid development of Non-Governmental organizations, the selfsupporting force of the government has less and less impact in this process, and the development of social entrepreneurship requires more and more of itself, and philanthropic capital and private donations have already been unable to meet its development needs.

\section{A COMPARISON BETWEEN THE SOCIAL ENTREPRENEURSHIP SUPPORT SYSTEM FOR COLLEGE STUDENTS IN BRITAIN AND AMERICA AND THAT IN CHINA}

\subsection{Colleges and Universities Have Different Levels of Support for Talent Training}

Compared with developed countries, China's social entrepreneurship activities are actually at a very preliminary starting stage. There are two main reasons. Firstly, the curriculum and teaching system of social entrepreneurship in Chinese universities are still not perfect and teachers are in short supply. The establishment of courses on social entrepreneurship is conducive to improving the ability level of college students' social entrepreneurs. In the United States and the United
Kingdom, social entrepreneurship education has already set up relevant curriculum systems and carried out relevant scientific research in this regard. Secondly, China's colleges and universities have not yet formed a system and other public entrepreneurship incubation platform. Foreign universities have long had successful experience. For example, Harvard and Stanford have long set up relatively complete experimental incubation platforms and condensed out successful experience. Their laboratory has a complete teaching system, teaching through the problems in the process of research, research organization, analysis data, group discussion, writing reports and so on process to improve college students' ability to analyze problems and team spirit, cultivate students entrepreneurship theory and combining the actual situation, finally can freely using the innovation theory to solve specific problems in society. Such incubating platform is exactly what Chinese university lacks temporarily at present.

\subsection{The Content of Government Policy Varies from Country to Country}

It can be seen from the above that the UK and the US have great support in policy. From the tax, related departments support and financial aspects to give social entrepreneurship great support. Although China has introduced preferential measures and related policies to encourage college students to start their own businesses, in fact, the policy for social entrepreneurship is still lacking.

In addition, although China has paid more and more attention to social entrepreneurship of college students in recent years, college students' cognition of this aspect is still relatively low, and some of them even know nothing about it. According to the survey, the main reason is that the promotion of relevant policies is not ideal in real life. In addition, college students have less access to government policies and lower requirements for policy improvement, which results in the dispensable state of relevant policies. It can be seen that the government needs to strengthen the promotion in this aspect, so that more college students pay more attention to this aspect. 


\subsection{The Degree of Closeness Between Social Enterprises and College Students' Social Entrepreneurship Is Different}

Comparatively speaking, the British and American countries are more closely related to social enterprises and social entrepreneurship. British and American countries will provide a lot of relevant training opportunities and technical education in this field. On the basis of learning the operation mode of enterprises, they will organize social entrepreneurs to set up enterprise alliance for membership system and share theories and practical experience. And China is deficient in this respect relatively.

In addition, China's social entrepreneurship model actually has certain limitations, lack of innovation ability, lack of practical operation experience, college students in this process lack of experience, innovation is not enough, so the benefits of social entrepreneurship is naturally not high.

\subsection{Non-governmental Organizations Have Different Influences on Social Entrepreneurship of College Students}

First of all, in the process of promoting the development of social entrepreneurship, the UK and the US have improved the legal rules and regulations of ngos and created a good environment for ngos. In contrast, ngos in China lack relevant policy support, leading to a lack of efficiency in their own operations. It cannot give full play to the voluntary, non-profit and public welfare characteristics of Non-Governmental organizations, nor can it timely solve the problem of limitations in the public service. Secondly, in order to improve the credibility of ngos, British and American countries will establish corresponding supervision mechanisms. However, China's ngos lack a sound monitoring and evaluation mechanism.

In addition, charities provide funding for social entrepreneurship in the UK and US. However, the support of charities in China is far less than that of the United States and Britain. The public's awareness of public welfare and charity needs to be improved. Charitable donation and asset investment from various institutions may not be timely. Various reasons may lead to the lack of funds for college students' social entrepreneurship in the initial stage.

\section{THE REFERENCE OF THE SOCIAL ENTREPRENEURSHIP SYSTEM OF FOREIGN COLLEGE STUDENTS TO CHINA}

\subsection{Improving the Education System for College Students to Engage in Social Entrepreneurship}

First of all, China should construct a social entrepreneurship education system integrating teaching, learning, research and practice. As early as more than ten years ago, the business school training system of foreign universities has long taken social entrepreneurship as a key course. In fact, our universities have been working hard in this respect. As early as 2007, Hunan University had set up a teaching system and courses closely related to social entrepreneurship, and also set up a related entrepreneurship research center. At that time, Hunan University had infiltrated the social entrepreneurship activities into the second class of students, continuously combined the professional knowledge and ideological and political education of students, and built an education model integrating industry, learning and research on this basis. So, it's very effective. Since then, other universities have also learned from the model of Hunan University, including Tsinghua University and Peking University, and carried out relevant research in this area. On the basis of the practice of social entrepreneurship in China, the teaching system suitable for China's current education is constantly explored. Moreover, quite a few teachers in China are also committed to introducing the excellent theories of developed countries into China in terms of innovation and entrepreneurship. Although in this process, due to the national conditions, economic conditions and social environment of China and foreign countries have certain obstacles to the spread of theory, but our entrepreneurs still insist on the combination of excellent theory and basic conditions of China, so that it can better adapt to the development of China.

Secondly, Chinese colleges and universities should build social entrepreneurship incubation platform. At present, China's entrepreneurship incubation system is still in a state to be improved. Fear of difficulties will appear in the process of college students' social entrepreneurship, and the campus social entrepreneurship atmosphere is not strong. Therefore, colleges and universities should timely help college students and give corresponding guidance, so that students have the ability to 
incubate potential and experienced public welfare organizations together. Foreign universities, such as Harvard and Stanford, have long set up relatively complete experimental incubation platforms and condensed out successful experience. Their laboratory has a complete teaching system. During the teaching process, the students' ability to analyze problems and team spirit are constantly improved through problem research, investigation and organization, data analysis, group discussion, report writing and other processes. Therefore, many colleges and universities in China also follow the example of these excellent schools abroad, and successively set up incubation centers for college students' social entrepreneurship, and also provide incubation support for college students' social entrepreneurship. The contents can refer to the social incubator function Settings of public welfare organizations. It is not only necessary to provide some office conditions, including water and electricity networks, venues, etc., but also to provide public services, such as tax handling and civil affairs registration, to facilitate the incubation of college students' social entrepreneurship.

In addition, institutions of higher learning with conditions should set up corresponding management organizations for social entrepreneurship activities of college students, or set up special departments in secondary colleges of the school for management. In this way, the social entrepreneurship activities of college students can be uniformly managed, and at the same time, various projects can be guided and professionally planned. These departments can also provide various resources for social entrepreneurship organizations, so as to effectively promote the sustainable development of college students' social entrepreneurship activities.

\subsection{Formulating Feasible Policies to Support College Students' Social Entrepreneurship}

According to the specific needs of social entrepreneurship development, the Chinese government should formulate practical and feasible policies to support college students' social entrepreneurship. The policy should clarify the rights and obligations of social entrepreneurship, as well as the nature, form and purpose of the organization, so as to make the operation of social entrepreneurship activities more standardized and legal.
In terms of taxation, China still lacks relevant policies. Many western countries in order to support the development of social entrepreneurship, income tax, business tax, tariff and other aspects have given attention. China should adopt different methods according to the different income and scale of social entrepreneurship organizations, and at the same time, some subsidies and tax exemption politics can be provided to relevant entrepreneurial organizations. In addition, China should also learn from reasonable and excellent policies from foreign countries, such as the use of tax laws to govern and regulate organizations, so as to improve the operation problems arising from the commercialization of social entrepreneurship activities.

At the same time, the Chinese government can refer to foreign experience to set up investment funds in the field of social entrepreneurship, so as to broaden the source channels of social entrepreneurship funds. At present, there are three modes of guiding funds for venture capital investment in China, including investment by the National Development bank, financial investment by local governments or investment by state-owned venture capital companies. Through government investment, the capital needed in the process of social entrepreneurship has been effectively guaranteed.

\subsection{Social Enterprises Provide Practical Training Opportunities for Social Entrepreneurship}

China's social organizations can learn from the experience of developed countries, establish associations similar to enterprise alliance, and on the basis of the association, form an alliance with social entrepreneurs as the main body. Through these alliances and associations, a large number of technical and training opportunities are provided to the people who need them — college students, which is undoubtedly conducive to their development in this field. In this process, social organizations and college students' social entrepreneurship promote and improve each other.

In addition, social enterprises can provide opportunities for college students to visit and practice, and have systematic learning. In the process to give instructions to college students in management, let the students learn to the enterprise management in the process of the college students social entrepreneurship can not only improve their management ability, make up for the inadequate 
experience weakness, can also promote entrepreneurship mode to continuous improvement and innovation, so as to make the social entrepreneurship activities can do both ends in the capital operation and social benefits.

\subsection{Ngos Should Improve Relevant Institutions and Mechanisms and Provide Necessary Support}

Facts have proved that ngos in developed countries such as the UK and the US have been skilled in participating in various activities related to social entrepreneurship and have established relatively sound operating mechanisms, including supervision mechanisms and communication mechanisms. China can refer to the way of getting along with non-governmental organizations in developed countries to promote the social entrepreneurship organizations of college students in China.

First, ngos need policy support to make their operations more efficient. As mentioned above, although the government plays a leading role in social and economic development, it still needs to make full use of the power of ngos in terms of public services and give full play to the characteristics of ngos as voluntary, public welfare and non-profit organizations, so as to solve the problems existing in public services. In the process of promoting the development of social entrepreneurship, foreign governments including the UK have improved the legal rules and regulations of ngos and created a good environment for ngos.

Secondly, ngos should improve the supervision and evaluation mechanism. In the process of NGO development, there will be many problems, and these problems will affect the credibility of NGO. To improve this situation, developed countries such as Britain and the United States will set up corresponding monitoring mechanisms. This mechanism can be divided into internal and external aspects. In terms of internal supervision mechanism, NGOS are highly efficient. First of all, they elect a board of directors within the organization. The elected board of directors must supervise the senior staff, so as to protect the reputation of ngos. In the external supervision mechanism, in order to prevent the managers of ngos from corruption, the funded personnel should supervise ngos, especially in financial and management aspects. This is not only conducive to the effective allocation of resources, but also to the improvement of efficiency.

In addition, charities provide foundation and platform support. It is vital that charities provide start-up and working capital for social entrepreneurship activities. Our society can increase the publicity of charities, so that the public can have a more comprehensive understanding of social entrepreneurship, so as to attract charitable donations and investment from various institutions, which can alleviate the embarrassing situation of insufficient funds in the period of social entrepreneurship. The improvement of people's living and economic level will promote the continuous understanding of charity and pay more attention to the vulnerable groups in society. The social cognition will drive the fund donation for social entrepreneurship and provide necessary fund and platform support for college students' social entrepreneurship.

\section{CONCLUSION}

Due to the late start of Chinese college students in social entrepreneurship, the current development is not comprehensive, so it still needs the support from the government, non-governmental organizations, universities, social enterprises and other aspects. Through the comparison with Britain and the United States, we can learn from all these aspects of experience to promote the development of college students' social entrepreneurship in China.

\section{AUTHORS' CONTRIBUTIONS}

This paper is independently completed by Cheng Su.

\section{REFERENCES}

[1] Zeng Deming, et al. [J] Finance and Economics, 2009 (3) : 80-84.

[2] Zuo Guo-Guo-Xing Fei Yexuan and Liu Lianzhi, Problems and Path Thinking of College Students' Social Entrepreneurship Education [J] Journal of Chengdu Aviation Vocational And Technical College, 2016 (1), 31-33.

[3] Zhao Lingyun, New Exploration of Social Entrepreneurship Education in Colleges and Universities - Taking the teaching of Social Enterprise Entrepreneurship as an example [J] 
Journal of Shanghai Youth Management Cadre Institute.2013 (1) : 12-16.

[4] Pan Jiajun, Liu Huanming, Discussion on college Students' Employment Promotion Mode based on social Entrepreneurship practice - Empirical Analysis on 80 college students' associations and some social organizations in 15 provinces $[\mathrm{J}]$, Journal of Hunan University of Science and Technology: Social Science Edition, 2012 (2) : 174-177.

[5] Yan Zhonghua. Social Entrepreneurship [J], Tsinghua University Press, 2008:34-26.

[6] Gao Yuan, Zhang Deqin, Research on College Students' Social Entrepreneurship from the perspective of "Mass Entrepreneurship and Innovation" [J], Modern Education Management, 2017, (7), 119-123.

[7] Ying Yongsheng, On strengthening the Government Responsibility of College Students' Entrepreneurship [J] Journal of Nanchang Hangkong University: Social Science edition, 2013 (9) : 109-114. 